\title{
JUURNAL
}

of Health Inequalities

\section{Report from the Calisia World Conference on Family Health, Kalisz, Poland, 9-10 June 2019}

\author{
Kinga Janik-Koncewicz \\ Health Promotion Foundation, Nadarzyn, Poland
}

ADDRESS FOR CORRESPONDENCE: Kinga Janik-Koncewicz, Health Promotion Foundation, 51 Mszczonowska St., 05-830 Nadarzyn, Poland, phone: +48 2237800 22, e-mail: biuro@promocjazdrowia.pl

\section{CONFERENCE OUTLINE}

The Calisia World Conference on Family Health was organised by the European Observatory of Health Inequalities at President Stanisław Wojciechowski State University of Applied Sciences in Kalisz, and by the Health Promotion Foundation (Fundacja "Promocja Zdrowia"), in collaboration with the World Prevention
Alliance in Lyon, France, and with the City of Kalisz. The conference took place in Kalisz, the oldest city in Poland, located near the centre of the country. It began on 9 June 2019 with a ceremony at the Wojciech Bogusławski Theatre in Kalisz. The second day involved scientific workshops divided into four sessions (see Box 1 below).

BOX 1. Calisia Conference programme outline

\section{Day 1: 9 June 2019 - Inaugural ceremony}

Welcome addresses

Welcome lecture by Professor Witold Zatoński, European Observatory of Health Inequalities, Health Promotion Foundation: One hundred years of health in Poland

Welcome lecture by Professor Peter Boyle, World Prevention Alliance in Lyon, France, and Professor Andrzej Wojtyla, President Stanisław Wojciechowski State University of Applied Sciences in Kalisz: Health, wellbeing, and family

Laudation in honour of Professor Jonathan Samet by the Rector of the State University of Applied Sciences in Kalisz Keynote lecture by Professor Jonathan Samet, Colorado School of Public Health, USA: The environment and health inequalities: problems and solutions

Piano recital by Professor Zbigniew Raubo

Day 2: 10 June 2019 - Scientific workshop

Session 1. Smoking and health: preparing for the tobacco endgame?

Video address: Allan Brandt, Professor of the History of Science, Harvard University, USA

Chair: Mateusz Zatoński, Health Promotion Foundation, Poland

Speakers:

- Cliff Douglas, Vice President for Tobacco Control, American Cancer Society, Professor of University of Michigan, USA

- Rob Branston, Associate Professor, Institute for Policy Research, University of Bath, UK

- Lilia Olefir, Executive Director, “Life” Advocacy Center, Ukraine

Discussant: Mark Parascandola, Program Director, National Cancer Institute, USA 
Session 2. Completing the cardiovascular revolution: smoking, alcohol, diet, and air pollution

Chairpersons: Tomasz Zdrojewski, Chairman of the Public Health Committee of the Polish Academy of Sciences, Poland; Marcin Wojnar, Medical University of Warsaw, Poland

Speakers:

- Piotr Bandosz, Medical University of Gdańsk, Poland; University of Liverpool, UK

- Zbigniew Gaciong, Director of the Clinic of Internal Medicine, Hypertension, and Angiology, Medical University of Warsaw, Poland

- Jacek Moskalewicz, Institute of Psychiatry and Neurology in Warsaw, Poland

- Carlo La Vecchia, Professor at the Department of Clinical Sciences and Community Health, University of Milan "La Statale", Italy

- Eva Negri, Professor at the Department of Biomedical and Clinical Sciences, University of Milan "La Statale", Italy

- Christina Ciecierski, Professor at Northeastern Illinois University, Chicago, USA

Discussants: Tomasz Zdrojewski, Chairman of the Public Health Committee of the Polish Academy of Sciences, Poland;

Mindaugas Štelemėkas, Health Research Institute, Lithuanian University of Health Sciences, Lithuania

\section{Session 3. Building a healthier community: Kalisz as the city of healthy families}

Introduction: Krystian Kinastowski, the Mayor of the City of Kalisz, Poland

Chair: Kinga Janik-Koncewicz, Health Promotion Foundation, Poland

Speakers:

- Sonia Angell, Professor at Columbia University, Columbia University; former Deputy Commissioner, NYC Health Department, USA

- Małgorzata Stelmach, MSD Women's Health Foundation, Warsaw, Poland

- Kinga Janik-Koncewicz, Health Promotion Foundation, Nadarzyn, Poland

- Aleksandra Herbeć, University College London, UK

Discussant: Krystian Kinastowski, the Mayor of the City of Kalisz, Poland

\section{Session 4. Closing session}

Chair: Witold Zatoński, European Observatory of Health Inequalities, Health Promotion Foundation, Poland

Speakers:

- Leif Edvard Aarø, Specialist Director, Norwegian Institute of Public Health: Declaration from the Calisia World Conference on Family Health 2019

- Michał Kleiber, Polish Academy of Sciences, Poland

\section{Pre-conference event: 9 June 2019}

Ecumenical ceremony (National Sanctuary of Saint Joseph in Kalisz)

- Krzysztof Wojcieszek, Pedagogium Higher School of Social Sciences, Warsaw, Poland: Religion and health

- Witold Zatoński, European Observatory of Health Inequalities, Health Promotion Foundation: Role of Cardinal Józef Glemp in building a healthier Poland

Ewa lżykowska (soprano) and Marek Gasztecki (bass) - Classical music recital

\section{Post-conference event: 11 June 2019}

Polish-American Collaborations in Public Health: Tobacco Control and Clean Air (American Center Warsaw),

co-organised by the Health Promotion Foundation and the US Embassy in Poland

Speakers:

Sonia Angell, Deputy Commissioner at the New York City Department of Health and Mental Hygiene, USA

Paweł Chęciński, Director of the Department of Health Policy for the City of Warsaw, Poland

Cliff Douglas, Vice President for Tobacco Control, American Cancer Society, USA

Mark Parascandola, Tobacco Control Research Branch in the Division of Cancer Control and Population Sciences at the National Cancer Institute, Washington, USA

Jonathan Samet, Dean of the Colorado School of Public Health, USA

Mateusz Zatoński, Health Promotion Foundation, Poland

Witold A. Zatoński, European Observatory of Health Inequalities, Health Promotion Foundation, Poland 
The Calisia Conference brought together scientific and medical experts, local public health activists, and policymakers, to discuss the state of health in Poland and the public health challenges facing this country, and Europe more broadly. The key themes of the conference included: one hundred years of health in Poland, premature mortality, healthy ageing, the tobacco endgame, alcohol and health, air pollution, cardiovascular revolution, and building healthy communities. The conference also provided an opportunity to begin work on the Calisia Declaration for Public Health. Over 100 participants listened to lectures and presentations from 27 renowned international scientists, researchers, and policymakers (see Box 2 below).

\section{BOX 2. Speakers at the Calisia World Conference on Family Health (in alphabetical order)}

Leif Edvard Aarø, PhD, Specialist Director, Norwegian Institute of Public Health, professor of social psychology, University of Bergen 1987-2014. Professor Aarø was one of the initiators of the WHO Study on Health Behaviour in School Aged Children. He has evaluated behaviour change interventions in Norway and Sub-Saharan Africa. In 2008 he received the Golden Honorary Award of the Polish Health Promotion Foundation.

Sonia Angell, MD, MPH, is an urban public health and policy expert. She is a former Deputy Commissioner (2014-2019) and Director of the Cardiovascular Disease Program (2004-2011) at the New York City Health Department, and Senior Advisor of Global Noncommunicable Diseases at the U.S. CDC (2011-2014). She is an assistant clinical professor of medicine at Columbia University.

Piotr Bandosz, PhD, physician, researcher and academic teacher. Interested in epidemiology of noncommunicable diseases and modelling of health policy interventions. Co-author of Polish national studies on the prevalence of cardiovascular disease risk factors and several scientific papers evaluating the potential effects of structural food policies. Currently employed by the University of Liverpool and Medical University of Gdańsk.

Peter Boyle, President of the International Prevention Research Institute, Lyon, France; former Director of the International Agency for Research on Cancer (IARC/WHO). He led the EUROCAN+PLUS project which developed priorities for coordination of cancer research in Europe and was Editor of the World Cancer Report 2008 and the State of Oncology 2013, State of Oncology in Africa 2015. Professor Boyle was featured in a previous issue of the Journal [1].

Allan M. Brandt is the Amalie Moses Kass Professor of the History of Medicine at Harvard University. His book on the social and cultural history of cigarette smoking in the United States, The Cigarette Century (2007), received the Bancroft Prize and the Welch Medal. His work focuses on social and ethical aspects of health, disease, medical practices, and global health in the twentieth century.

J. Robert Branston, PhD, is Associate Professor in Business Economics at the University of Bath School of Management (UK). His primary research interests on the global tobacco industry include tobacco taxation, industry pricing strategies, and industry profitability. He has a growing portfolio of publications in leading academic journals and has shared his expertise with the UK and lrish governments.

Christina Ciecierski, Associate Professor of Economics at Northeastern Illinois University. Her research focuses on the impacts of price and policy variables on consumer lifestyles. The course of her career has centered on promoting health equity among young adults, immigrants, populations of low socio-economic status in the state of Illinois as well as populations native to less- and mid-developed countries in the world.

Cliff Douglas is Vice President for Tobacco Control and Director of the Center for Tobacco Control at the American Cancer Society. He is also Adjunct Professor at the University of Michigan School of Public Health. Previously he was a tobacco control policy advisor for the U.S. Surgeon General and served as Special Counsel on Tobacco Issues in the US Congress.

Zbigniew Gaciong, Professor of medicine, head of the Department of Internal Medicine, Hypertension and Angiology of the Medical University of Warsaw, Poland. Member of multiple national and international scientific association. He is an author of over 100 works published in most prestigious medical journals. For last years, he's been a member of Medical University authorities.

Aleksandra Herbeć, PhD, is a psychologist and a behavioural scientist based at the Centre for Behaviour Change at University College London and Consultant at Health Promotion Foundation in Poland, where she works on developing and evaluating complex interventions. Over the past decade she has conducted research and published on tobacco control, smoking cessation, medication adherence, and digital health.

Kinga Janik-Koncewicz, Project Director at the Health Promotion Foundation. In years 2001-2016, she was a senior researcher at the Department of Epidemiology at the Cancer Center and Institute of Oncology in Warsaw, Poland. Involved in conducting national and international research projects and intervention programmes. In 2015 she was awarded an Elphinstone PhD scholarship of the University of Aberdeen and commenced doctoral research with the Epidemiology Group, Institute of Applied Health Sciences. 
Krystian Kinastowski (born 1979), the Mayor of the City of Kalisz, non-partisan; ran for mayor as the candidate of KWW Wszystko i Samorządny zgodnie dla Kalisza (Everything and Self-Governing unanimously for Kalisz) in the 2018 Polish local elections - he received the most votes after the first round, and won in the second round receiving 63.5\% of votes. An architect by education.

Michał Kleiber is currently Professor at the Polish Academy of Science, Vice-President of the European Academy of Sciences and Arts and President of the European Community for Computational Methods in Applied Sciences. He was President of the Polish Academy of Sciences and Chairman of its Future Studies Committee, Advisor to the President of Poland and Minister of Science and Digitalization.

Carlo La Vecchia is Professor of Medical Statistics and Epidemiology at the School of Medicine at the University of Milan. Dr La Vecchia serves as an editor for numerous clinical and epidemiologic journals. He is among the most renowned and productive epidemiologists in the field with over 2,090 peer-reviewed papers in the literature and is among the most highly cited medical researchers in the world.

Jacek Moskalewicz, PhD, Head of the Department of Studies on Alcoholism and Drug Dependence at the Institute of Psychiatry and Neurology in Warsaw, Poland. Sociologist, for over 30 years involved in social and epidemiological research on alcohol, drugs and mental health. Member of the WHO experts' advisory panel. Recipient of Jellinek Memorial Award and Chevalier Cross of Polonia Restituta.

Eva Negri works at the Department of Biomedical and Clinical Sciences of the University of Milan. She has authored over 1,000 papers in peer-reviewed journals in the field of epidemiology and biostatistics of cancer and other non-communicable diseases. Her main interests are the implementation and analysis of epidemiological studies and of systematic reviews/meta-analyses of published data and individual participant data.

Lilia Olefir is Executive Director of the NGO Advocacy Center "LIFE" since 2017. Ms. Olefir works on building relationship and cooperation with policy makers, media, international organizations, tobacco control community, healthcare professionals and civil society organizations to advance tobacco control policies in Ukraine. Ms. Olefir is leading advocacy projects on WHO FCTC and MPOWER implementation.

Mark Parascandola, PhD, epidemiologist with the Behavioral Research Program in the Division of Cancer Control and Population Sciences and Center for Global Health at the National Cancer Institute. He received his Doctorate in Philosophy of Science from Cambridge University. Dr Parascandola also completed an NCl Cancer Prevention Fellowship. He has authored numerous published articles on epidemiologic research methodology, cancer risk assessment, and tobacco control.

Jonathan M. Samet a pulmonary physician and epidemiologist, is Dean of the Colorado School of Public Health and Professor in the Department of Epidemiology and Environmental \& Occupational Health. For more information please see article: The environment and health inequalities: problems and solutions on pages 21-27 [2].

Mindaugas Štelemèkas leads the Health Research Institute and is an associate professor in the Department of Preventive Medicine at the Lithuanian University of Health Sciences, and is a board member of the Lithuanian Tobacco and Alcohol Control Coalition. He has participated in a number of projects related to NCDs and alcohol-attributable harm, resulting in national and international publications and reports.

Małgorzata Stelmach is president of the MSD Women's Health Foundation. She graduated from the Medical Academy in Warsaw and is professionally connected to the pharmaceutical market. She's personally dedicated to health literacy and health promotion. For many years she's been organizing educational campaigns on the prevention of cervical cancer.

Krzysztof Wojcieszek is a molecular biologist, philosopher, and teacher. He specializes in the creation, application, and testing of prevention programs. Many of these are widely used in Poland. The solutions used in these programs have an innovative character, such as active work with a large group. He publishes a lot, also in the field of human philosophy, and is a consultant to many institutions, co-author of the Polish National Sobriety Program (2018), and lecturer at several universities.

Marcin Wojnar is a graduate of the Medical Academy in Warsaw. He is a psychiatrist, Professor at the Warsaw Medical University and head of the Department of Psychiatry at the Medical University of Warsaw. He is also a visiting Professor in the Department of Psychiatry at the University of Michigan in Ann Arbor, USA.

Andrzej Wojtyła, paediatrician, assistant professor in medical sciences, former Minister of Health and Social Welfare, Deputy Minister of Health, and Chief Sanitary Inspector in Poland. He was a visiting Professor at Georgetown University and secretary general of the World Organization of Rural Medicine. Since 2018, he has served as rector of the President Stanisław Wojciechowski State University of Applied Sciences in Kalisz.

Mateusz Zatoński is the vice-president of the Polish Health Promotion Foundation, and Research Associate at the Department for Health, University of Bath, UK. He is the author of numerous publications in tobacco control, alcohol policy, epidemiology, health economics, and history. He has taught and conducted research on public health and history at several academic institutions globally, including University College London and Harvard University. 
Witold Zatoński, MD, Professor of medical sciences, honorary doctor of the University of Aberdeen in United Kingdom. Between 1966 and 1979 he worked as an internist (post-doctoral degree) and as a biochemist at the Medical Academy in Wrocław, Poland. Then, until 2016 he was the director in the Division of Epidemiology and Prevention at the Maria Skłodowska Curie Memorial Cancer Centre and Institute of Oncology in Warsaw. Professor Zatoński is the founder and president of the Health Promotion Foundation.

Tomasz Zdrojewski MD, PhD, Professor at the Medical University of Gdańsk; clinician, internist, academic teacher and researcher at the Medical University of Gdańsk and the National Institute of Public Health - National Institute of Hygiene in Warsaw. An expert in the field of monitoring, prevention, and modelling of non-communicable diseases and health policy. Since 2012, chairman of the Public Health Committee of the Polish Academy of Sciences.

\section{INAUGURAL CEREMONY}

Professor Andrzej Wojtyła gave a welcoming speech and greeted all guests and participants (Photo 1). This was followed by a welcome address from Mayor Krystian Kinastowski.

The first welcome lecture, entitled "One hundred years of health in Poland", was given by Professor Witold Zatoński, representing European Observatory of Health Inequalities and the Health Promotion Foundation. He showed how trends in life expectancy in Poland have changed during the last 100 years, in comparison with other countries. Poland experienced a phase of stagnation in life expectancy between 1960 and 1990, followed by a sharp increase. Professor Zatoński tried to explain the possible causes of these health changes, providing as an example changes in rates of infectious diseases and infant mortality control. He underlined the persistent problem of premature deaths in Poland and the role of tobacco smoking and alcohol consumption [3].

Professor Peter Boyle delivered his lecture entitled "Health, wellbeing, and family", issues of rising importance that should be addressed in public health discussions. $\mathrm{He}$ proposed considering the family as a unit and looking at a variety of factors other than illness, like poverty, that could have an impact on health and wellbeing [4].

After a laudation in his honour presented by Rector Andrzej Wojtyła, Professor Jonathan Samet gave the first conference keynote lecture, "The environment and health inequalities: problems and solutions" (Photo 2). Professor Samet showed evidence for the contribution of environmental factors to health inequalities. He emphasised the role of ambient air pollution and tobacco smoking in health disparities worldwide and in Poland, and suggested potential solutions to reduce the burden of diseases attributed to smoking and pollution [2].

\section{SCIENTIFIC MEETING}

The first scientific session was devoted to "Smoking and health: preparing for the tobacco endgame?" and was moderated by Dr Mateusz Zatoński from the Health Promotion Foundation, Poland, and Dr Mark Parascandola from National Cancer Institute, USA [5]. The panellists discussed potential measures that can help address the persistent problem of smoking (Photo 3 ). The session opened with a video address from Professor
Allan Brandt from Harvard University, USA (see Webappendix 4), who gave an overview of the key themes in the history of tobacco control. Dr Zatoński then summarised tobacco control developments in Poland since the 1990s, dividing the smoking epidemic in the country into three distinct phases. Professor Cliff Douglas presented American Cancer Society activities in capacity-building, fostering a stronger global tobacco control community, and areas of priority for future work [6]. Dr Rob Branston from the University of Bath talked about the importance of taxation in driving declines in smoking rates, and why increasing tobacco prices should be viewed with enthusiasm, not suspicion, by politicians [7]. Finally, Lilia Olefir, representing "Life" Advocacy Center in Ukraine, outlined the recent developments in tobacco control in Ukraine, which has seen some vibrant grassroots advocacy, but also strong tobacco industry opposition [8]. To finish off, Dr Parascandola discussed the key themes that emerged from the panel [9].

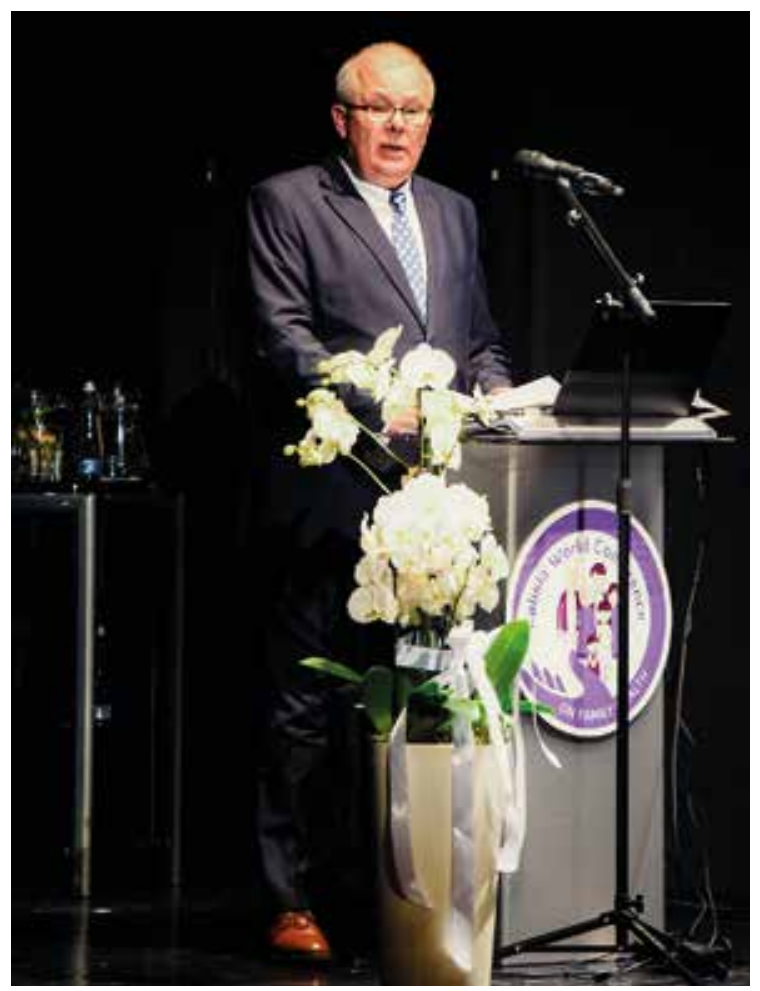

Рното 1. Welcome address by Rector Andrzej Wojtyła 


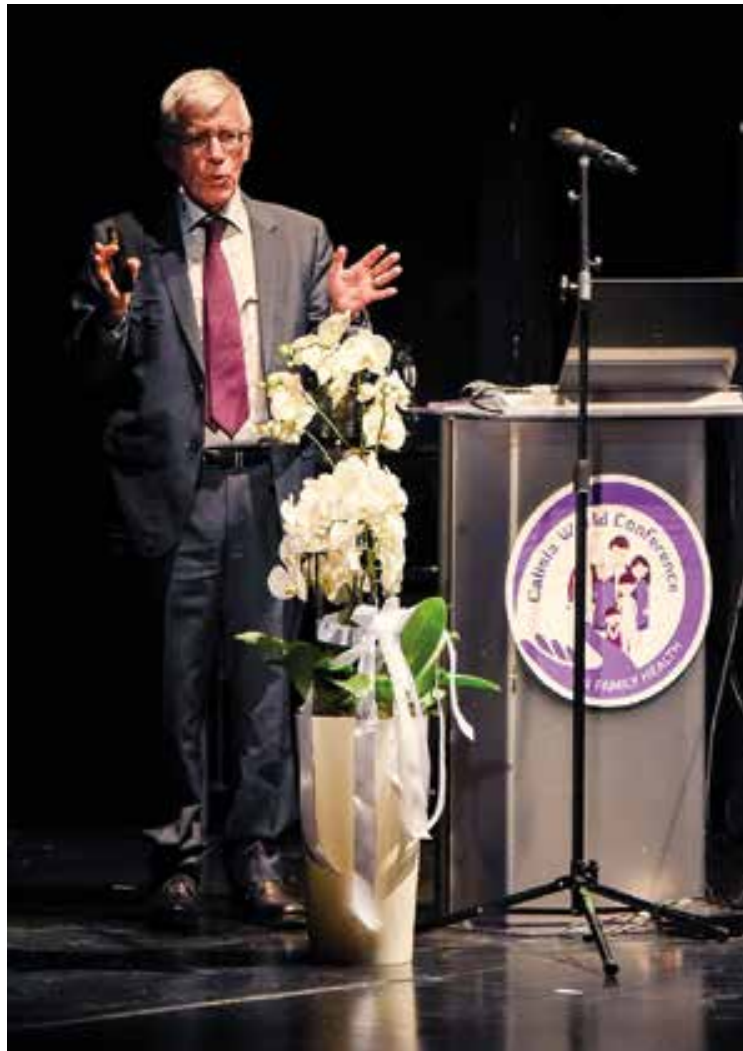

PHOTO 2. Keynote lecture by Professor Jonathan Samet

Session number two was co-chaired by Professor Tomasz Zdrojewski from the Polish Academy of Sciences and Professor Marcin Wojnar from Medical University of Warsaw (Photo 4). It was devoted to the still unfinished cardiovascular revolution and to the most important drivers of cardiovascular diseases - smoking, alcohol, diet, and air pollution. Professor Zdrojewski started the session with a short discussion of mortality rates due to heart diseases in Poland, in comparison to other European countries, and the preventability of non-communicable diseases, especially cardiovascular diseases [10]. Dr Piotr Bandosz's (Medical University of Gdańsk) lecture concerned the role of cholesterol and atherogenic factors of diet in the development of cardiovascular disease. He presented data confirming the end of favourable changes in the structure of fat consumption in Poland and proposed possible interventions [11]. Professor Zbigniew Gaciong from the Medical University of Warsaw summarised evidence of the causal relationship between alcohol consumption and cardiovascular diseases. The conclusion was that alcohol beverages should not be viewed as substitutes for the well-proven cardiovascular risk reducing behaviours such as healthy diet, physical activity, and pharmacotherapy [12]. Dr Jacek Moskalewicz (Institute of Psychiatry and Neurology in Warsaw, Poland) outlined the evolution of alcohol policy during the time of transition in Poland, in the 1980s and 1990s [13]. Profes-

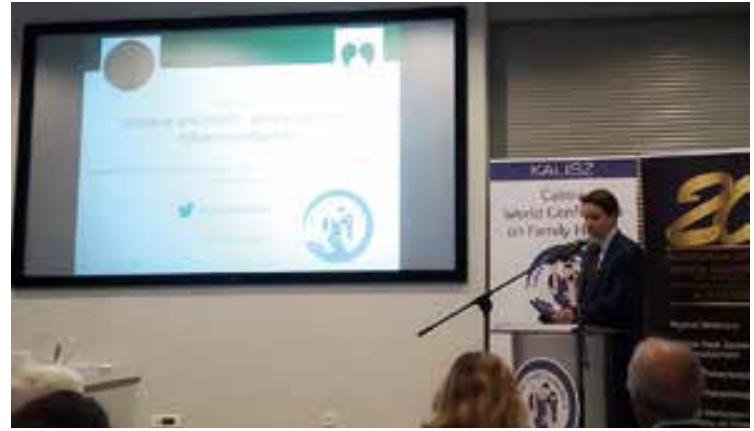

Рното 3. Dr Mateusz Zatoński opening the conference sessio

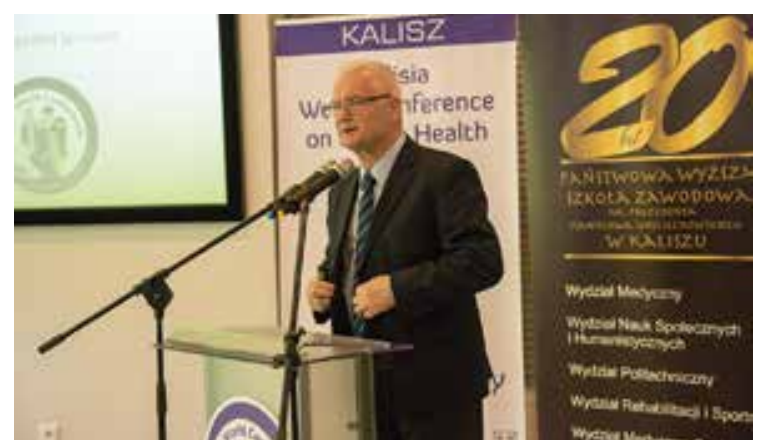

PHOTO 4. Professor Tomasz Zdrojewski during the session on "Completing the cardiovascular revolution: smoking, alcohol, diet, and air pollution

sor Carlo La Vecchia (Department of Clinical Sciences and Community Health at the University of Milan "La Statale"), presented data from a series of Italian studies on various aspects of the Mediterranean diet and the risk of cardiovascular diseases and several neoplasms. Besides the Mediterranean diet, he underlined the role of healthy body weight in disease prevention [14]. Professor Eva Negri (University of Milan "La Statale") talked about gender differences in smoking-related diseases [15]. Dr Mindaugas Štelemėkas from Health Research Institute, Lithuanian University of Health Sciences, spoke about the Lithuanian experience in alcohol control in recent decades, and the potential role of alcohol policy changes in health improvement [16]. Finally, Christina Ciecierski, Professor at Northeastern Illinois University, Chicago, USA, summarised potential influences of economic mechanisms on alcohol and tobacco consumption in Poland. The session ended with a summary of key points by Prof. Tomasz Zdrojewski.

The third session of the conference focused on the importance of building healthy local communities, in Kalisz and elsewhere, and was co-chaired by Kinga JanikKoncewicz from the Health Promotion Foundation and Mayor Krystian Kinastowski [17]. The aim of the session was to propose possible programmes and initiatives that could be implemented to improve health indicators and wellbeing in the Kalisz region, as well as share the best international examples of such interventions (Photo 5). 


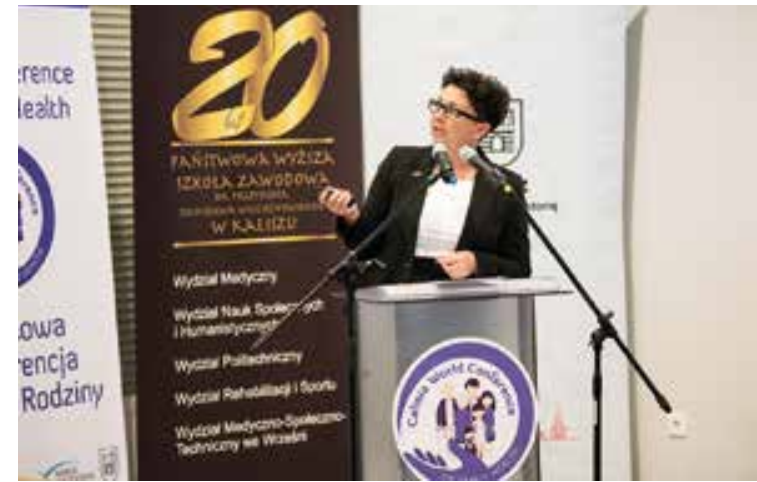

PHOTO 5. Kinga Janik-Koncewicz (Health Promotion Foundation) opening the session on "Building a healthier community: Kalisz as the city of healthy families"

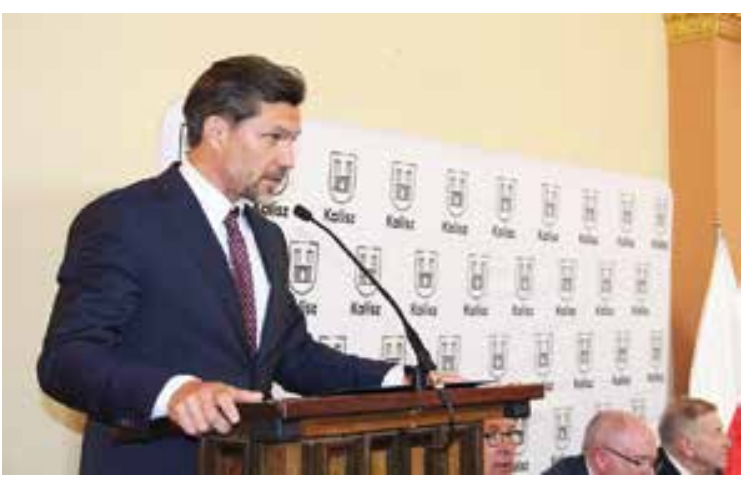

РНОTO 7. Krystian Kinastowski, Mayor of Kalisz

The first speaker, Mayor Kinastowski, introduced the audience to basic demographic information on the City of Kalisz and its health service capacity [18]. Dr Sonia Angell, former Deputy Commissioner of the New York City Department of Health then talked about the risk factors of cardiovascular diseases and specific recommendations of interventions based on experiences from New York City [19]. Next, Kinga Janik-Koncewicz gave a presentation about possible activities aimed at preparing a diagnosis of health for the Kalisz region. She briefly presented one of the Health Promotion Foundation's current projects, focused on building health competencies in the Lower Silesia region of Poland, which could be adapted and implemented in the Kalisz region [20, 21]. This was followed by Aleksandra Herbeć's (University College London) presentation focused on innovative programmes for the treatment of tobacco dependence [22]. Małgorzata Stelmach presented a summary of achievements in cervical cancer control in Poland, including the Kalisz region [23]. Finally, Mayor Kinastowski summarised the session and took questions and comments from the audience.

The fourth session was chaired by Professor Witold Zatoński and devoted to the genesis of the Declaration of the Calisia World Conference on Family Health, 2019. Work on the Declaration was coordinated by Professor Leif Aarø (Norwegian Institute of Public Health) (Photo 6)

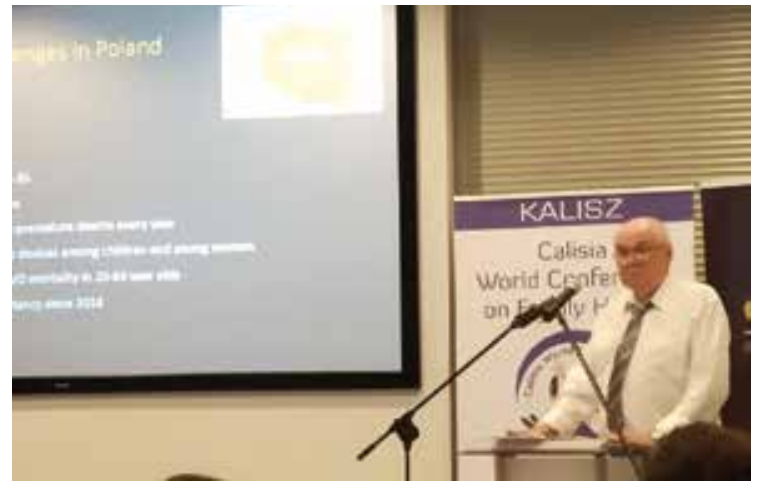

Рното 6. Professor Leif Aarø presenting the Declaration from the Calisia World Conference on Family Health, 2019

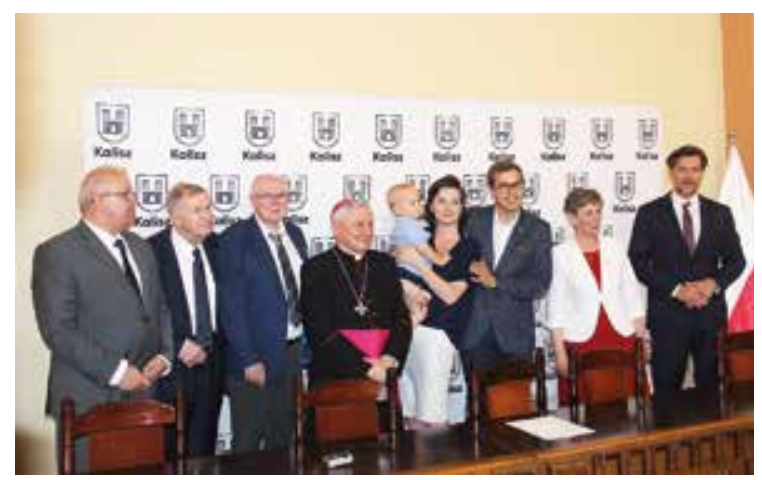

PHOTO 8. Closing ceremony at Kalisz City Hall

[24]. Finally, Professor Michał Kleiber from the Polish Academy of Sciences presented the Foresight strategy, describing activities influencing public policy in future.

At the end of the scientific workshop, the Mayor of Kalisz invited conference speakers and participants to City Hall for the closing ceremony (Photos 7, 8). All speakers received letters of gratitude from Rector Andrzej Wojtyła.

\section{PRE-CONFERENCE EVENT}

On 9 June, the conference organiser hosted an ecumenical meeting in the National Sanctuary of Saint Joseph in Kalisz. The event brought together representatives of different religions in Poland to address the role of family health in public health challenges in Poland. Professor Witold Zatoński presented the history and role of Cardinal Józef Glemp in the Health Promotion Foundation's efforts to build a healthier Poland (Photo 9).

On 11 June, a post-conference meeting entitled "Polish-American Collaborations in Public Health: Tobacco Control and Clean Air" was held at the American Center Warsaw, and co-organised by the Health Promotion Foundation and the US Embassy. The meeting involved NGO representatives, scientific and medical experts, and policymakers, who discussed not only the health benefits of tobacco control and clean air, but also the policy implications and instruments necessary to achieve pub- 


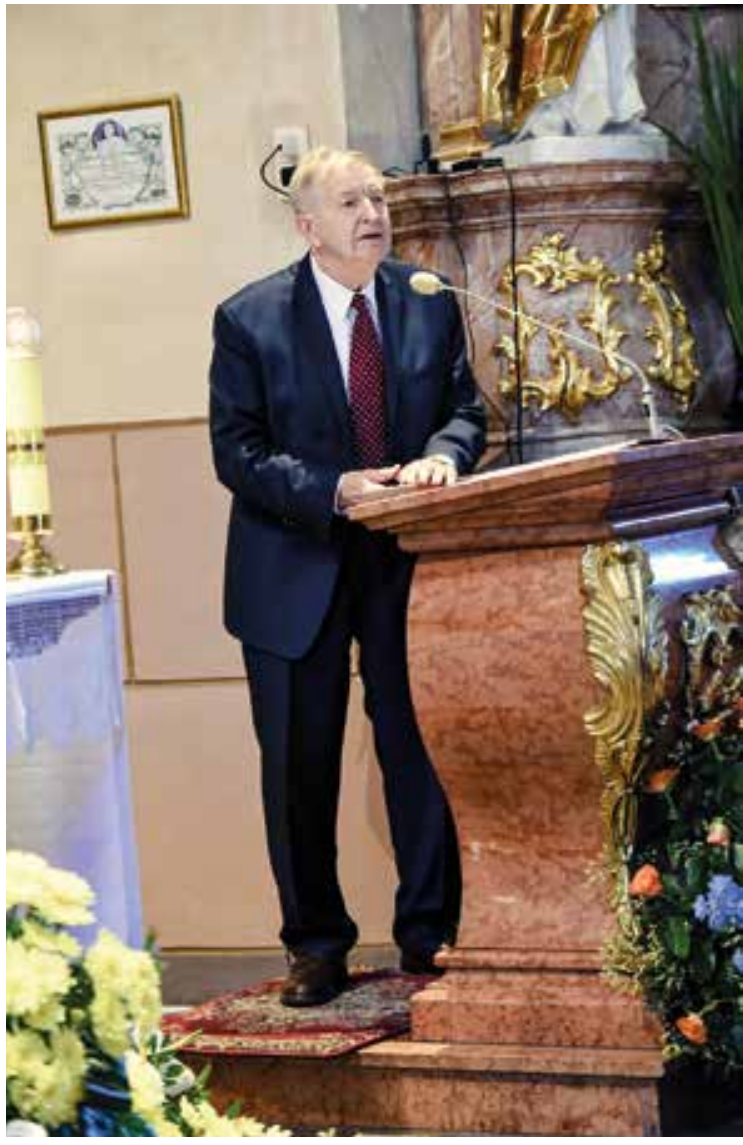

PHOTO 9. Professor Witold Zatoński presenting the history of collaboration with Cardinal Józef Glemp Post-conference event

lic health results [25]. Presenters included: Sonia Angell, Deputy Commissioner at the New York City Department of Health and Mental Hygiene, Pawel Chęciński, Director of the Department of Health Policy for the City of Warsaw, Cliff Douglas, Vice President for Tobacco Control, American Cancer Society, Mark Parascandola, epidemiologist with the Tobacco Control Research Branch in the Division of Cancer Control and Population Sciences at the National Cancer Institute, in Washington, D.C., Jonathan Samet, Dean of the Colorado School of Public Health, Mateusz Zatoński, Health Promotion Foundation, Poland, Prof. Witold Zatoński, Director of the European Observatory of Health Inequalities (Photos 10, 11). During the meeting, Mr Paweł Chęciński presented general demographic and health situation in Warsaw city as a baseline for discussion on potential future collaboration between meeting's participants (see slides in Webappendix 1).

\section{ACKNOWLEDGEMENTS}

KJK would like to thank Mateusz Zatoński and Scott Thompson for help with the English edition of the text. Photos included in the publication were taken at the

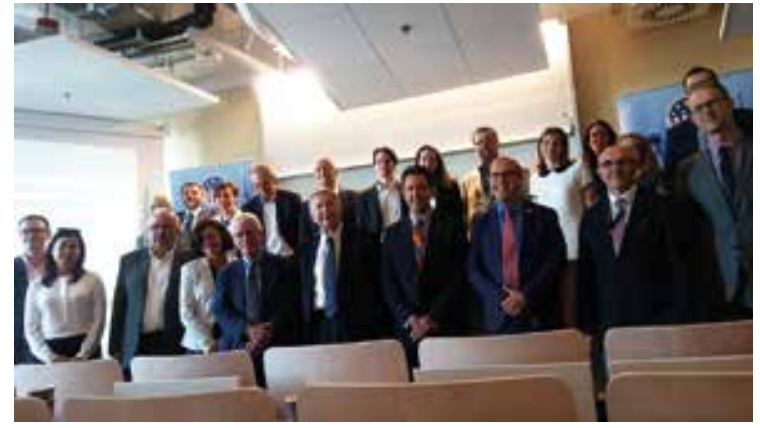

PHOTO 10. Polish-American Collaborations in Public Health: Tobacco Control and Clean Air meeting

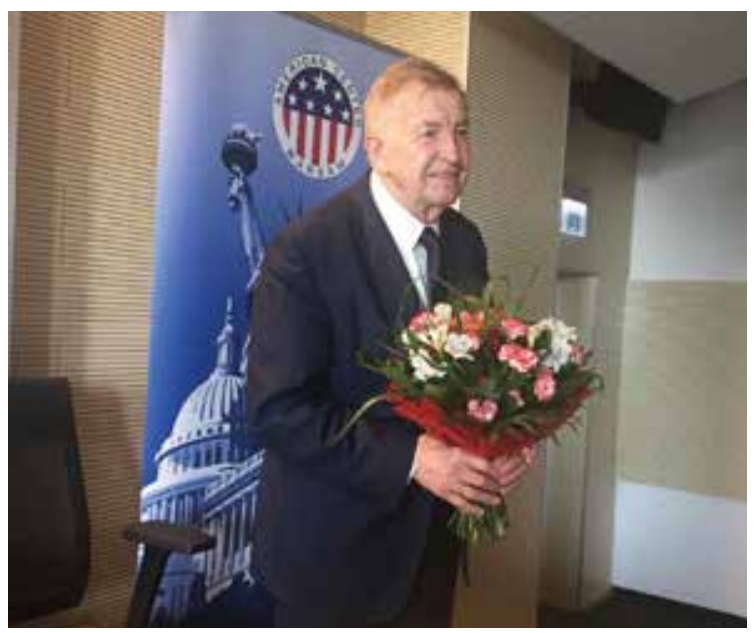

PHOTO 11. Professor Witold Zatoński celebrates his $77^{\text {th }}$ birthday with participants of the meeting on $11^{\text {th }}$ June

request of conference organisers. Photos 10 and 11 were taken and shared by meeting participants.

\section{DISCLOSURE}

The author reports no conflict of interest.

\section{References}

1. Boyle P. Global public health - challenges and leadership. J Health Inequal 2018; 4: 55-61.

2. Samet JM. The environment and health inequalities: problems and solutions. J Health Inequal 2019; 5: 21-27.

3. Zatoński WA. One hundred years of health in Poland. J Health Inequal 2019; 5: 11-19.

4. Boyle P, Wojtyła A. Health, wellbeing, and family. J Health Inequal 2019; 5: 20.

5. Brandt A, Zatoński M. Tobacco endgame: where are we and what are the challenges ahead. J Health Inequal 2019; 5: 28-30.

6. Douglas CE. A public health perspective on combating youth e-cigarette use while aiming at the bull's eye: the end of combustible tobacco use. J Health Inequal 2019; 5: 21-32.

7. Branston JR. Tobacco taxation: a key tool for public health. J Health Inequal 2019; 5: 33. 
8. Olefir L. Tobacco control advocacy in Ukraine: recent progress and the tobacco industry opposition. J Health Inequal 2019; 5: 34-35.

9. Parascandola M. Challenges for the tobacco endgame. J Health Inequal 2019; 5: 36-37.

10. Zdrojewski T. Completing the cardiovascular revolution: smoking, alcohol, diet, and air pollution. J Health Inequal 2019; 5: 38

11. Bandosz P. Cholesterol and cardiovascular mortality in Poland. Are we going in the right direction? J Health Inequal 2019; 5: 39.

12. Gaciong Z. Alcohol and the heart. J Health Inequal 2019; 5: 40.

13. Moskalewicz J. Evolution of alcohol policy in Poland during the transition period. J Health Inequal 2019; 5: 41.

14. La Vecchia C. Mediterranean diet, cancer, and cardiovascular risk in a network of Italian studies. J Health Inequal 2019; 5: 42.

15. Negri E. Gender differences in smoking-related diseases. J Health Inequal 2019; 5: 43.

16. Stelemekas M. Alcohol, policy, and public health in Lithuania: what was done and what might the effects be? J Health Inequal 2019; 5: 44.

17. Janik-Koncewicz K. Building a healthier community: Kalisz as the city of healthy families. J Health Inequal 2019; 5: 45-46.

18. Kinastowski K. Summary of the Mayor Krystian Kinastowski’s presentation at the Calisia World Conference on Family Health. J Health Inequal 2019; 5: 47.

19. Angell SY. Generating health in the New York City. J Health Inequal 2019; 5: 48 .

20. Janik-Koncewicz K, Rosik K, Młoźniak I, et al. Public health students as health educators: health awareness and behaviours among primary care professionals and public health students conducting a health literacy intervention. J Health Inequal 2019; 5: 89-95.

21. Janik-Koncewicz K, Herbeć O, Zatoński M, et al. Building health literacy in a Polish region: protocol for the POWER project in Lower Silesia. J Health Inequal 2018; 4: 27-30.

22. Herbeć A. The future of treatment of tobacco dependence harnessing the technology to deliver hybrid interventions. J Health Inequal 2019; 5: 49.

23. Stelmach M. Cervical cancer - still a serious problem for public health in Poland. What is needed to solve it? J Health Inequal 2019; 5: 50.

24. Aarø LE. Declaration from the Calisia World Conference on Family Health 2019. J Health Inequal 2019; 5: 51-52.

25. Polish-American Collaborations in Public Health: Tobacco Control and Clean Air. Available from: https://pl.usembassy. gov/polish-american-collaborations-in-public-health-tobacco-control-and-clean-air/ (accessed: 21 June 2019). 